\title{
ORNITHONYSSUS SYLVIARUM (ACARI: GAMASIDA: MACRONYSSIDAE) A CAUSE OF PRURITIC DERMATITIS FOR POULTRY FARM WORKERS IN SOHAG GOVERNORATE, EGYPT
}

\author{
By
}

NOHA S. AHMED* and AMAL M. AHMED

Departments of Medical Parasitology, Faculty of Medicine, Sohag University, Egypt ( ${ }^{*}$ Correspondence: nohasammer@yahoo.com, Mobile 01273126001)

\section{Abstract}

People urban areas have shared environment with pets and animals, mainly birds and rodents. These animals harbor zoonotic parasites, as mites of the suborder Mesostigmata. The mites were Dermanyssus gallinae (the poultry red mite) and Ornithonyssus sylviarum \& O. bursa, the primary hosts are Rattus norvegicus and Rattus rattus. These species of mites may be harmful to animals, as well as to people working in the shops or potential pet owners. The study dermatological and parasitological evaluated the workers $(n=30)$ in a poultry farming at El-Kawther, Sohag Governorate for mite pruritus and to identify mites in the period from July to October 2019. Detailed history was taken from all workers. Full examination was done. Workers gave history of exposure to insects bite in the poultry farm where they work. Workers were advised to collect any insects that can bite them or come in contact with their skin, which were referred to Parasitology unit, Sohag University, for identification both by light microscopy and SEM. Examination of all workers revealed that $70 \%(21 / 30)$ of them complained of itching of variable intensity. Age of participants ranged from 38-41 years all of them were males. About pruritus, all cases had insidious onset of pruritus, commonly in summer season (16/21 \& 76.19\%), especially at night (18/21 \& 85.7\%), Recurrence of the symptoms after treatment occurred ( $11 / 21 \& 52.18 \%)$. Patients' examination showed that skin lesions were more on the exposed sites forming excoriated papules $(71.4 \%)$ and urticarial lesions $(28.6 \%)$. Insects collected where examined by using light and SE microscope. Arthropods were identified as $O$. sylviarum in all cases.

O. sylviarum is a causative agent of human mite dermatitis in Sohag Governorate. The identification of the cryptic species should be tolerable by amalgamating morphological study with molecular analyses of mitochondrial DNA sequence.

Keywords: Ornithonyssus (O) sylviarum, dermatitis, poultry workers, SEM, Upper Egypt.

\section{Introduction}

Avian mite dermatitis is a pruritic skin disease caused by the bites of blood-sucking mites, which live as ectoparasites of wild and domestic birds, when they temporarily leave their usual hosts to feed on humans or other mammals (McClain et al, 2009). Three species are generally responsible for the disease in humans: Dermanyssus gallinae (poultry red mite), a parasite of wild and domestic birds with worldwide distribution (Cafiero et al, 2008), Ornith-onyssus sylviarum (northern fowl mite), a pest of chickens in temperate regions (Mc-Clain et al, 2009) and Ornithonyssus bursa (tropical fowl mite), a tropical and subtropical mite of wild and household birds less commonly to feed on man (Belmonte et al, 2012; Wambier et al, 2012).
Unlike the various forms of the disease in birds, the clinical manifestations in humans do not vary, regardless of the species responsible, and are typically those represented in the present subject. Cutaneous reactions in man are non-specific and difficult to diagnose without a degree of clinical suspicion. They consist of pruritic erythematous and/or urticarial papules, often marked by a pinpoint red spot on the top (McClain et al, 2009). Mites often travel through cracks in doors, floors, walls, and ceilings but also can gain access to living areas through ventilation ducts and air conditioning units (Regan et al, 1987). Their bite and crawling on the skin was sometimes noticed by patient and intense itching was observed about 1 to 3 days after the mite attacked the skin. Patients often suffered from pruritus worst at 
night (Auger et al, 1979). Bird mites sometimes can be scraped from the skin and observed under light microscopy (Koh et al, 2011). The problem was aggravated in urban areas owing to the increase in bird nests built on the roofs or in the external parts of air-conditioners (Ribeiro et al, 1992; Krinsky, 1983; Oliv-eira et al, 2012).

In Egypt, a total of 31 mites' species were infesting the two common resident birds in many governorates (Morsy et al, 1999) and 29 species were infesting two migratory birds Coturnix c. coturnix and Sturnus v. vulgaris (Mazyad et al, 1999). Besides, so many mites' species were reported infesting domestic and wild rodents and man Egyptian Governorates for example Qualyobia (Morsy et al, 1994; Mazyad and El-Kadi, 2015), Menoufia (Bakr et al, 1995), Suez Canal (El-Kady et al, 1995), South Sinai (El-Kady et al, 1998), Alexandria (Salah et al, 2013a, b) and Dakahlia (Eladl et al, 2018)

This study aimed to identify the problem of avian mite dermatitis among poultry farm workers and to identify the causative mites El-Kawther, Sohag Governorate.

\section{Patients and Methods}

Informed consent was obtained from all participants included and after explanation of the objectives of the study.

Selection of patients: A total of 30 male workers in chicken farming with aged from 38-41years were examined. Medical sheets were filled out on each one. Complete dermatological examination for dermatitis or insect-bites was done sometimes added by touch and hand-lens. Mite samples were collected at poultry farm during daylight hours, from a variety of sites, as beneath feed toughs, inside cage fittings and fastening clips, under egg conveyor belts, and under manure belts with a fine brush and held in closed petri dishes.in both by light and SEM microscopy Light microscope: Samples were put in $10 \% \mathrm{KOH}$ solution at $37^{\circ} \mathrm{C}$ water bath overnight for clearance. Then, samples were dehydrated in ascending ethanol $(70 \%, 80 \%$, $90 \%, 95 \% \& 100 \%)$ followed by dehydration in absolute ethanol, xylene, and then xylene before mounting on slides with a drop of distyrene (Krantz and Walter, 2008).

SEM: Mites were fixed in 5\% glutaraldehyde for $24 \mathrm{hrs}$, washed 4 times in soda cacodylate acid $(\mathrm{pH} 7.3) 10 \mathrm{~min} / \mathrm{each}$, fixed in osmium tetraoxide $1 \%$ for $2 \mathrm{hrs}$, washed 3 times in soda-cacodylate acid $10 \mathrm{~min} / \mathrm{each}$ and dehydration in a graduated acetone series $(30,50,60,70,80,90,95, \& 100 \%$, $5 \mathrm{~min} /$ each. Samples were then incubated at $20-25^{\circ} \mathrm{C}$ and stuck on double scotch tape carbon and coated with gold (Hayat, 1981).

Examination and photographs of mites samples were performed in SEM Unit, Central Laboratory, Sohag University, Egypt.

\section{Results}

Workers 21/30 (70\%) complained of variable degrees of skin dermatitis. Skin examination showed that lesions were excoriated papules and urticarial ones. Excoriated popular lesions were in $(15 / 21$ or $71.4 \%)$ and urticarial lesions in $(6 / 21$ or $28.6 \%)$. Skin lesions were on different body parts, the commonest sites were forearms (38.1\%) and legs (38.1\%). By light and SEM mites proved to be Ornithonyssus sylviarum. Details were given in table (1) and figures (1, $2 \& 3)$.

Table 1: Skin lesions in workers suffered from pruritus.

\begin{tabular}{|l|c|c|l|c|c|}
\hline Lesion & Frequency & Percent & Site & Frequency & Percent \\
\hline Excoriated papules & 15 & 71.4 & Foot & 2 & 9.5 \\
Urticarial lesions & \multirow{3}{*}{6} & \multirow{2}{*}{28.6} & Forearm & 8 & 38.1 \\
& & & Leg & 8 & 38.1 \\
& & & Neck & 1 & 4.8 \\
& & & & 2 & 9.5 \\
\hline Total & 21 & 100 & & 21 & 100 \\
\hline
\end{tabular}

Discussion

There was a wide variety of zoonotic diseases transmitted from mites infested birds to man. Pigeons, chickens, starlings, canaries, and parakeets are reservoirs of mites zoonotic infection (Regan et al, al, 1987). 
Species most frequently implicated in human bite were $D$. gallinae and $O$. sylviarum (Belmonte et al, 2012; Wambier and Wambier, 2012). When these mites were unable to take blood meals from birds, they look for alternative hosts (Collgros et al, 2013). In humans, this often led to the development of pruritic dermatitis (Bellanger et al, 2008).

The most important point related to human infestation is that physicians are usually unfamiliar with the dermatitis caused by several zoonotic ectoparasites (Haag-Wackernagel, 2005; Cafiero et al, 2008; Collgros et $a l, 2013)$. It was actually very difficult to diagnose mite infestation from the cutaneous reactions in humans; as the reactions were uncharacteristic, infestations often misdiagnosed (Kavallari et al, 2018). The lack of guidelines and/or recommendations, and insufficient awareness of physicians/dermatologists with mites infestation and their eco-biology could delay patient proper treatment.

Generally, true incidence of avian mite dermatitis is lacking, the studies were underreported due to its uncommon environ-mental reason (Bellanger et al, 2008). Reports of avian mite dermatitis in the literature also are scarce.

The present study reported $O$. sylviarum as a causative agent of avian mite dermatitis at Sohag Governorate. Few scanty studies were available as case reports. This agreed with Cafiero et al. (2018) in Italy they used TEM and/or SEM to analyze the arthropods related to 26 urban outbreaks of pruritic dermatitis among 60 adults \& 6 children lived and/ or worked in Southern Peninsular and Insular Italian Regions reported O. sylviarum as a causative agent of human dermatitis, as well as $O$. bursa and $O$. bacoti (Castelli et al, 2015; Cafiero et al, 2016). Halawa et al. (2019) studied the mites infestation rate associated with865 wild birds in lower Egypt (Cairo, Qaluobia and Beheira) and upper Egypt (Bani-Swaif, El-Fayoum and Sohag), over two successive years from June 2016 to May 2018, identified O. sylviarum in Sohag Governorate, and O. sylviarum in Beheira
Governorate. Despite the high diversity of this mite, worldwide 2500 species of many families were associated with birds especially in tropics (Proctor and Owens, 2000).

Detailed history was taken from all workers who are in close contact to chickens in El-kawther, Sohag Governorate poultry farm and revealed that most of them complained of itching of variable degrees. In this study, the onset of pruritus was insidious in all cases. The mite's bite and crawling on the skin is sometimes noticed by the patient. In general, however, intense itching is not observed until about 1 to 3 days after the mite makes contact with the skin (Auger et al, 1979).

In the present study, most of the workers reported that pruritus was more common in the summer season, especially at night. When bird mites are no longer able to obtain blood meals from nesting birds, they begin their nocturnal migration to find suitable hosts and so patients often report that pruritus was worst at night (Auger et al, 1979).

In the present study, symptoms recurrency after receiving symptomatic treatment occurred in about half of the cases. Avian mite dermatitis should be suspected when unexplained, recurrent, arthropod-bite-like eruptions occur in humans in urban settings and symptomatic therapies are unsuccessful (Cafiero et al, 2018). Also, in more than half of our cases, there was positive family history of similar condition. Those most at risk of developing avian mite dermatitis include poultry workers but there have also been sporadic case reports from the USA and Japan including multiple infestations within a family (Uesugi et al, 1994). The present study showed that the majority of patients who complaining of pruritus gave history of the presence of bird nests near their home/ workplace. Mites usually gained access to man from neighboring birds' nests, either directly or indirectly through windows, doors, and vents to search for a new host, favoring human parasitism (Orton et al, 2000; Oliveira et al, 2012). 
Skin examination of the patients showed that the lesions were in the form of excoriated papules and urticarial lesions. The lesions were apparent on different body parts, but, more on the exposed sites such as upper and lower limbs and the face. This agreed with Regan et al. (1987); Haag-Wackernagel (2005); Castelli et al. (2015); Mazyad and El-Kadi, 2015) and Cafiero et al. (2018), they detected that the skin eruptions mainly on arms, and hands, as well as legs face.

\section{Conclusion}

All patients with pruritic dermatitis were successfully treated with systematic antihistaminic. Confusion may exist with similar mite species, primarily $O$. sylviarum which may cohabit with $D$. gallinae and pose similar problems for hen. The mite-agent recovered was the Ornithonyssus sylviarum, the known ecto-parasite of rodents worldwide.

\section{Recommendations}

1- Rodenticides must be applying in chicken farming before every breeding cycle.

2- Farm must be sprayed with friend acaricides before every chicken breeding cycle.

2 - A pedal impregnated with $2 \%$ Malathion for cleaning shoes before entering the farm.

\section{References}

Bakr, ME, Morsy, TA, Nassef, NE, EI Meligi, MA, 1995: Mites infesting commensal rodents in Shebin El Kom, Menoufia Governorate. J. Egypt. Soc. Parasitol. 25, 3:853-60.

Bellanger, AP, Boris, C, Foulet, F, et al, 2008: Nosocomial dermatitis caused by Dermanyssus galli-nae. Infect Cont. Hosp. Ep. 29:282-3.

Belmonte Oliveira, C, Tonin, AA, Monteiro, SG, 2012: Parasitismo do acaro Ornithonyssus bursa em humanos no Sul do Brasil: Infestation by Ornithonyssus bursa in humans in southern Brazil. Acta Sci. Vet. 40:1091-3.

Cafiero, MA, Camarda, A, Circella, E, et al, 2008: Pseudoscabies caused by Dermanyssus gallinae in Italian city dwellers: A new setting for an old dermatitis. J. Eur. Acad. Dermatol. Venereol. 22: 1382-3.

Cafiero, MA, Raele, D, Mancini, G, Galante, D, 2016: Dermatitis by tropical rat mite, Ornithonyssus bacoti (Mesostigmata, Macronyssidae) in city dwellers: A diagnostic challenge. J. Eur. Acad. Dermatol. Venereol. 30:1231-3.
Cafiero, MA, Viviano, E, Lomuto, M, Raele, DA, Galante, D, et al, 2018: Dermatitis due to Meso-stigmatic mites (Dermanyssus gallinae, Ornithonyssus (O.) bacoti, O. bursa, O. sylviarum) in residential settings. J. Deut. Dermatol. Gesellsch.16:904-6.

Castelli, E, Viviano, E, Torina, A, et al, 2015: Avian mite dermatitis: An Italian case indicating the establishment and spread of Ornithonyssus bursa (Acari: Gamasida: Macronyssidae) (Berlese, 1888) in Europe. Int. J. Dermatol. 54:795-9.

Collgros, H, Iglesias-Sancho, M, Aldunce, M J, et al, 2013: Dermanyssus gallinae (chicken mite): an underdiagnosed environmental infestation. Clin. Exp. Dermatol. 38:374-377.

El Kady, GA, Makled, KM, Morsy TA, Morsy, ZS, 1998: Rodents, their seasonal activity, ecto- and blood-parasites in Saint Catherine Area, South Sinai Governorate, Egypt. J. Egypt. Soc. Parasitol. 28, 3:815-26.

El Kady, GA, Shoukry, A, El Said, AM, Raghab, DA, Habib, KM, Morsy, TA, 1995: Mites (Acari) infesting commensal rats in Suez Canal Zone, Egypt. J. Egypt. Soc. Parasitol. 25, 2: 417-25.

Eladl, AH, Hamed, HR, El-Shafei, RA, 2018: Prevalence of mites and their impact on laying hen (Gallus gallus domesticus) farm facilities in Egypt, with an analysis of deltamethrin residues in eggs and tissue. Avian Pathol.47, 2:161-71.

Haag-Wackernagel, D, 2005: Parasites from feral pigeons as a health hazard for humans. Ann. Appl. Biol. 147:203-10.

Halawa, A, Osman, S, Ahmed, H, 2019: Diversity and infestation rate of mites associated with some birds in upper and lower Egypt. Ann. Agric. Sci. Moshtohor 57:517-24.

Hayat, MA, 1981: Principles and Technique of Electron Microscopy. Vol. 1, $2^{\text {nd }}$ Ed., New Jersey University Park Press.

Kavallari, A, Küster, T, Papadopoulos, E, Hondema, L, Øines, Ø, et al, 2018: Avian mite dermatitis: Diagnostic challenges and unmet needs. Parasit. Immunol. 40:Pe12539.

Koh, WL, Liu, TT, Tay, YK, 2011: Formica tion due to true parasitic infection: Bird mites. Arch. Dermatol. 147:508-9.

Krantz, GW, Walter, DE, 2008: A Manual of Acarology. $3^{\text {rd }}$ Ed. Texas Tech University Press, ISBN-10:0896726207.

Krinsky WL, 1983: Dermatoses associated with the bites of mites and ticks (Arthropoda: acari). Int. J. Dermatol. 22:75-91. 
Mazyad, SAM, Morsy, TA, Fekry, AA, Farrag, AMK, 1999: Mites infesting two migratory birds, Coturnix c. coturnix (quail or simman) and Sturnus v.vulgaris (starling or zarzour) with reference to avian zoonosis. J. Egypt. Soc. Parasitol. 29, 3:745-61.

Mazyad, SA, El-Kadi, MA, 2015: Ornithonyssus (Acari: Macronyssidae) mite dermatitis in poultry field-workers in Almarg, Qalyobiya Governorate. J. Egypt. Soc. Parasitol. 35, 1:213-22.

McClain, D, Dana, AN, Goldenberg, G, 2009: Mite infestations. Dermatol. Ther. 22:327-46.

Morsy, TA, El Okbi, MMA, El Said, AM, Arafa, MAS, Sabry, AA, 1995: Demodex (Follicular mite) infesting a boy and his pet dog. J. Egypt. Soc. Parasitol. 25, 2:509-12.

Morsy, TA, Mazyad, SAM, Younis, MS, 1999: Feather and nest mites of two common resident birds in two ecologically different Egyptian Governorates. J. Egypt. Soc. Parasitol. 29, 2: 417-30

Morsy, TA, Michael, SA, Bassili, WR, Saleh, MSM, 1982: Studies on rodents and their zoonotic parasites, particularly Leishmania, in Ismailiya Governorate, A.R. Egypt. J. Egypt. Soc. Parasitol. 12, 2:565-85.

Morsy, TA, Zohdi, HW, Abdalla, KF, Nasr, ME, Ibrahim, AA, et al, 1994: Immunoglobulins in patients with atopic dermatitis due to mites infestation in Qualyobia Governorate, Egypt. J. Egypt. Soc. Parasitol. 24, 3:495-500.

Morsy, TA, Zohdi, HW, Abdalla, KF, El Fakahani, AF, Ibrahim AA, et al, 1994: Isolation of three species of mites from house dust of atopic dermatitis patients in Qualyobia Gover- norate, Egypt. J. Egypt. Soc. Parasitol. 24, 2: 323-32.

Oliveira, CB, Tonin, AA, Monteiro, SG, 2012: Parasitismo do ácaro Ornithonyssus bursa em humanos no Sul do Brasil. Acta Sci. Vet. 40: 1091-4.

Proctor, H, Owens, I, 2000: Mites and birds: diversity, parasitism and coevolution. Trends Ecol. Evol. 15:358-64.

Regan, AM, Metersky, ML, Craven, DE, 1987: Nosocomial dermatitis and pruritus caused by pigeon mite infestation. Arch. Intern. Med. 147:2185-7.

Ribeiro, VLS, Moojen, V, Telles, APD, 1992: Caso clínico: Ornithonyssus bursa: parasito de aves causando acaríases cutâneas em humanos no Rio Grande do Sul, Brasil. Ann. Bras. Dermatol. 67:31-4.

Saleh, AMA, Ali, HA, Ahmed, SAM, Mohammad, NM, Morsy, TA, 2013a: House dust mites: A risk factor to be considered for occupational safety or source of work-related allergens. J. Egypt. Soc. Parasitol. 43, No. 3:669-78

Saleh, AMA, Ali, HA, Ahmed, SAM, Mohammad, NM, Morsy, TA, 2013b: The effect of an intervention program in nurses' knowledge and performance regarding management of house dust mites in a military hospital. J. Egypt. Soc. Parasitol. 43, 3:821-40.

Uesugi, Y, Aiba, S, Suetake, T, et al, 1994: Multiple infestations with avian mites within a family. Int. J. Dermatol. 33:566-7.

Wambier, CG, Wambier, SP, 2012: Gamasoidosis illustrated, from the nest to dermoscopy. Ann. Bras. Dermatol. 87:926-7.

\section{Explanation of figures}

Fig. I: Cutaneous manifestations in patients due to infestation by $O$. sylviarum affected different body parts.

Fig. 2: light microscopy of $O$. sylviarum A: Adult female $(1 \mathrm{~mm})$ with dorsal shield, B: Anterior part with pedipalps $(\mathrm{Pa})$ and chelicerae $(\mathrm{Ch})$. Fig. 3: Identification of $O$. sylviarum by SEM. 1: Dorsal view showed idiosoma, Dorsal shield (Ds) with projecting shoulder abruptly narrowed posteriorly (arrows) and 4 pairs of legs (L1- L4). 2: Ventral view showed pedipalps (Pa), sternal shield (st), genitoventral shield (gs), anal shield (as) and 4 pairs of legs (L1- L4). 3: Reticulation on dorsal shield (arrows). 4: Reticulation on ventral shield (arrows). 5: Sternal shield with 2 pairs of seta (arrows). 6: Anal shield with three anal setae around anal opening (ao) (arrows).

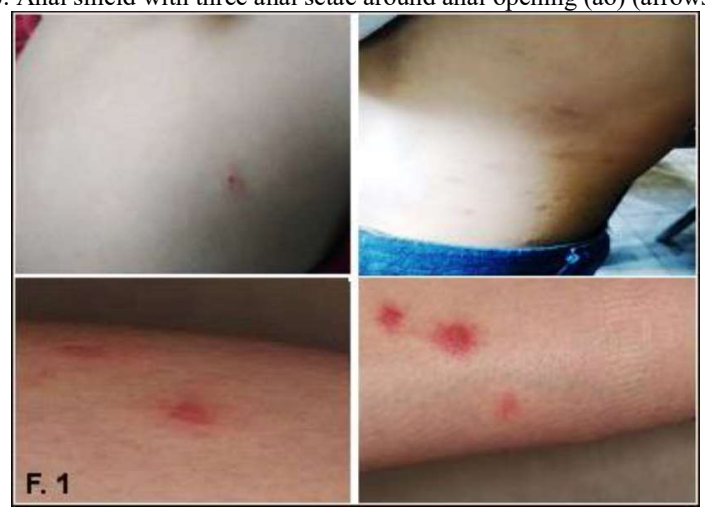



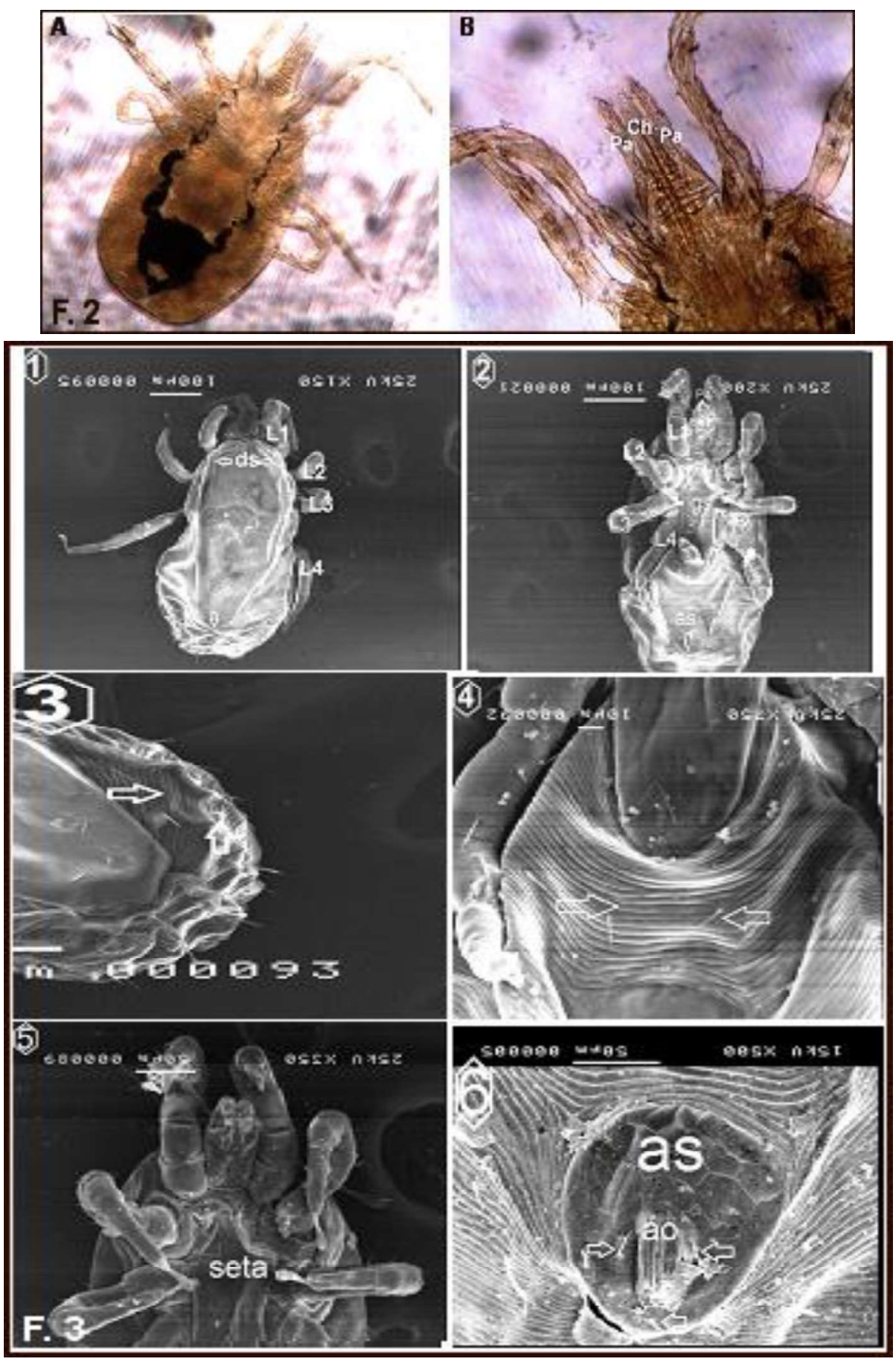